\title{
Bottlenecks in Expanding Science and Technology Education in Nepal: An Exploratory Study
}

\author{
Man Kumar Dhamala, ${ }^{1}$ Madan Koirala $\mathbb{D}^{1},{ }^{1}$ Ram Prasad Khatiwada ${ }^{D},{ }^{2}$ \\ and Rashila Deshar ${ }^{1}{ }^{1}$ \\ ${ }^{1}$ Central Department of Environmental Science, Tribhuvan University, Kirtipur, Kathmandu, Nepal \\ ${ }^{2}$ Institute of Science and Technology, Tribhuvan University, Kirtipur, Kathmandu, Nepal \\ Correspondence should be addressed to Rashila Deshar; rdeshar@cdes.edu.np
}

Received 3 July 2020; Revised 28 July 2021; Accepted 2 August 2021; Published 16 August 2021

Academic Editor: Ehsan Namaziandost

Copyright (C) 2021 Man Kumar Dhamala et al. This is an open access article distributed under the Creative Commons Attribution License, which permits unrestricted use, distribution, and reproduction in any medium, provided the original work is properly cited.

\begin{abstract}
Higher education and research for socioeconomic development are well recognized in developed and developing countries. Studies have shown that a high participation rate in higher education with a high share of Science, Technology, Engineering, and Mathematics (STEM) education is critical for competitiveness in the global market. Nepal would not fulfill people's aspirations for prosperity by perpetuating the status quo scenario of the education system. This study aimed at exploring and assessing the factors influencing science and technology education in Nepal and tried to assess the current status of science education and critically examine the factors affecting the development of science education in Nepal. The study used both primary and secondary data. The primary source of data is from interviews, observations, focused group discussions, and semistructured questionnaires. Secondary data were collected from National Examination Board, universities, colleges, and campuses. The study found a decreasing trend of student enrollment in science and technology (S\&T) education in Nepal. In addition, the results revealed a decreasing trend of women students, so it should be taken as a matter of concern. Some key bottlenecks identified were insufficient and broken physical infrastructures (classrooms, laboratories, and libraries); inadequate and incapable human resources; and improper management practices. However, the study results show positive perceptions of society towards S\&T education in Nepal. The study recommends developing modern infrastructures, building human resources, and improving management practices for better S\&T education.
\end{abstract}

\section{Introduction}

The importance of higher education and research for socioeconomic development is well recognized in all developed and developing countries $[1,2]$. The Organization for Economic Development and Cooperation (OECD) defines the role of tertiary education in the social and economic development of a country in four ways, namely, the formation of human capital (primarily through teaching); the building of knowledge bases (primarily through research and knowledge development); the dissemination and use of knowledge (primarily through interaction with knowledge users); and the maintenance of knowledge (primarily through intergenerational-storage and transmission of knowledge) [3].
According to the World Bank, tertiary education institutions have a critical role in supporting knowledge-driven economic growth strategies and constructing democratic, socially cohesive societies. Further, it assists in improving the institutional regime through the training of competent and responsible professionals needed for sound macroeconomic and public-sector management. In addition, its academic and research activities provide crucial support for the national innovation system. In conclusion, the norms, values, attitudes, and ethics that tertiary education institutions impart to students are the foundation of the social capital necessary for constructing healthy civil societies and cohesive cultures-the very bedrock of good governance and a democratic political system [3]. But many developing countries are struggling to address the mission of building knowledge bases. 
The widespread recognition that tertiary education is a significant driver of competitiveness in an increasingly knowledge-driven global economy has made high-quality tertiary education more important than ever in industrialized and developing countries [4]. On the other hand, Research and Development (R\&D) plays a significant role in productivity or economic growth. Therefore, developing countries should concentrate on R\&D to achieve sustained economic growth [5]. The rapid rise of the Republic of Korea, Finland, Singapore, Estonia, and China exemplifies how countries that have focused on generating and adopting knowledge have achieved dramatic economic growth. India is on a similar track.

The contribution of education, specifically science education, to national development and the role of science education in creating a climate of public opinion for the better use of science and technology in industrial development is highly significant, especially for underdeveloped and developing countries [2]. Furthermore, research has shown that a high participation rate in higher education with a high share of Science, Technology, Engineering, and Mathematics (STEM) education is critical for competitiveness in the global market [3].

The role of science education to a better understanding of the relationship between science and technology and social and environmental concerns is also essential [6]. Science, Technology, and Innovation (STI) are increasingly important for social, economic, and sustainable development [7]. Moreover, the formulation of effective STI policies is critical in facing the significant challenges ahead for achieving the 2030 Agenda, such as conserving freshwater (SDG 6), building resilient infrastructure, promoting inclusive and sustainable industrialization and fostering innovation (SDG 9), and combating climate change (SDG 13) [8].

Developed countries have prioritized Science, Technology, Engineering, and Mathematics (STEM) while expanding higher education. The Constitution of Nepal has linked science and technology with the country's overall sustainable development [9]. However, the priority on STEM education in Nepal has quite an investigable concern. In the long run, the expansion and prioritization of science and technology education in Nepal are not investigated, and the bottlenecks are not identified. Therefore, this study aimed at exploring and assessing the factors influencing science and technology education in Nepal. Specifically, this study tried to assess the existing status and conditions of science education, analyse trends, and critically examine the bottlenecks affecting the development of science and technology education in Nepal.

1.1. Review of Literatures. Nepal's first higher educational institute was established in 1918, and subsequently, the tertiary level of science and technology education started. The intermediate level of science education was then introduced in 1919. The formal Nepalese Bachelor of Science, an undergraduate degree, was started in 1945. Before, these courses were affiliated with different Indian universities. The importance of science education was widely recognized after the birth of democracy in Nepal in 1951. Various commissions were made to get suggestions for higher education and vocational training [10]. Analytical and enhancement aspects of science and technology education in Nepal started after restoring multiparty democracy in 1990. Literature shows that various attempts are made to identify overall governance problems in higher education and suggest encouraging people through aspirations for prosperity towards science and technology education [11].

The Asian Development Bank (ADB) has made many efforts to facilitate Nepal's employment and economic productivity. In this regard, $\mathrm{ADB}$ has emphasized providing better vocational education to the students to make them skillful [12]. In addition, the Central Bureau of Statistics (CBS) conducts a population census every ten years and periodically surveys Nepal's different social and economic aspects. According to CBS, most Nepalese youths are deprived of higher education due to sociopolitical instability and economic reason [13]. Similarly, the study on the situation of science and technology education in Nepal carried out by Joshi [14] in 2018 has made some concrete resolutions regarding education policy in Nepal. The significant comment provided by the study was on critical reforms required in delivering higher education outcomes for supporting Nepal's aspirations for its prosperity that would not be possible within the existing legal framework for universities.

Developed countries have prioritized Science, Technology, Engineering, and Mathematics (STEM) while expanding higher education. All developed economies have high shares of STEM graduates in higher education graduates, which is $35-50 \%$. The claims of STEM of technologically advanced countries like Finland, Israel, Sweden, and the Republic of Korea are $51.5 \%, 49.5 \%, 48.6 \%$, and $45.3 \%$, respectively. On the other hand, the United States of America, which has a STEM share of $35 \%$, faces a shortage of STEM human resources [14].

In 2015/16, Nepal's tertiary Gross Enrollment Rate (GER) of $14.6 \%$ is higher than the Low-Income Countries (LIC) average of $7.6 \%$ but lower than the Lower-MiddleIncome Countries (LMIC) average of $23.1 \%$. To get up the prosperity ladder, it is not enough for Nepal to compete with LIC but will have to compete with more prosperous countries. Therefore, despite the relatively high GER compared to the peers in the income group, increasing GER is a pertinent agenda for Nepal. Consistent with attaining a High-Income Countries (HIC) status, Nepal should increase the GER to $70 \%$ by 2050 , close to the HIC average of $73.4 \%$ for 2016 [14].

\section{Materials and Methods}

2.1. Conceptual Framework and Sample Design. The Ministry of Education, Science, and Technology, a governmental body responsible for the overall development of education in Nepal, has pointed out major problems of Nepal's science and technology in higher education. The problems are lack of legal policy and institutional infrastructures for the development of science and technology, slackness in the 
available policy implementation, insufficient investment and infrastructure, brain drain of available human resources, lack of establishment of a network for cooperation and partnership, and ineffective collaboration with the private sector for science and technology development [9]. Therefore, Nepal has to make a significant investment in science and technology to overcome these problems. Furthermore, Nepal has to make a substantial investment in developing scientists, experts, and skilled human resources in different disciplines for the country's sustainable development. Scientific research with appropriate technology development will only stop the brain drain by retaining the country's skilled and expert talents in the country. As a result, it will strengthen, reform, and restructure the scientific researchbased bodies in conformity with federalism [9].

Based on this theoretical background, this study explores the existing status and conditions of science education, so the key influencing factors of science and technology education, such as infrastructure and equipment, human resources, management, and socioeconomy, were considered. Furthermore, to critically examine the bottlenecks affecting science and technology education development, Nepal's political states and ecological zones were considered.

The survey has been carried out in the country's seven provinces and covering three ecological zones, namely, Mountain, Mid Hills, and Terai. Altogether, 50 academic institutions were sampled purposively from all provinces. The distribution of sample institutes was $9,5,10,7,7,5$, and 7 , respectively, from provinces 1 to 7 . According to the ecological zones, the sample distribution was 24,15 , and 11 from Terai, Mid Hills, and High Mountains. The sample institutes were identified and selected based on judgmental sampling as per the objective of the study. Institutions were from rural and urban settings showing differences in facilities and student numbers.

Key aspects such as access, physical infrastructure, human resources, and societal perception of science and technology education were considered in the study. For access, current science student enrolment and enrolment trends in universities were studied. Existing conditions of classrooms, labs, library, and instruments/equipment were assessed in physical infrastructure. Finally, existing faculties and their capacity enhancement training in science and technology education were studied in human resources.

2.2. Target Groups. The survey considered government, constituent, community, and private institutions running or with the potential to run science and technology education. The study involved science faculty/school/departments, university campuses involving the dean, head of the department, campus chief, faculty members, students, and other university-level stakeholders. On the other hand, it involved higher secondary schools involving headteachers (Principals) of higher secondary schools, science teachers, students, and other stakeholders. Moreover, the higher education institutions, including the universities and the campuses that are primary beneficiaries of the Higher Education Reforms Project (2014-2020), were the study's focus.
2.3. Survey Instruments. Both primary and secondary sources of information were used in response to the specific objectives of the study. Secondary data were collected from various sources, for example, government documents, published reports, official records at different universities and academic institutions, Department of Environment (DOE), and National Education Board (NEB). Enrollment trends were assessed using the data (for five years) of Tribhuvan University (the largest government university in Nepal) and Kathmandu University (a private university specializing in STEM education).

For collecting primary data, various instruments and tools were designed, pretested, and redesigned. The major tools deployed in this study were interviews, observations, focused group discussions (FGD), and structured and semistructured questionnaire surveys. We visited 118 classrooms and 127 laboratories in the surveyed academic institutions across the country. In addition, we interviewed 63 faculties, 49 parents, and 38 students to collect their opinions and perceptions on S\&T education. The collected data were tabulated using descriptive statistical tools and with the help of an Excel Spreadsheet. A three-step process was used for qualitative data, namely, data reduction, data display, and deriving meaning from the data. We first assessed enrollment trends and graduated in tertiary education from Tribhuvan University and Kathmandu University. Then, we studied the factors influencing S\&T education, and finally, we identified the key bottlenecks in expanding S\&T education in Nepal.

\section{Results}

3.1. Enrollment Trends. Tribhuvan University is the oldest and largest academic institution in the country. A seven-year student enrollment data from the five institutes of S\&T education (Institute of Science and Technology, IOST; Institute of Engineering, IOE; Institute of Medicine, IOM; Institute of Forestry, IOF; and Institute of Agriculture and Animal Sciences, IAAS) shows an increasing trend at IOM, IOF, and IAAS and decreasing trend for IOST and IOE (Figure 1). This finding is reflective of the general trend of enrollment in S\&T education in the country. Likely future decreasing enrollments in IOST and IOE need to be considered carefully as these institutes produce graduates who play important roles in expanding S\&T education and the country's future development. The university and the government need to work together to reverse the scenarios. Improvement in the teaching-learning environments, creating better job opportunities for the graduates, and recognizing the importance of S\&T graduates in societal development are recommended as possible ways.

The student enrollment number at Kathmandu University in the science and technology programs between 2013/2014 and 2016/2017 (based on the data availability) shows an overall decreasing trend. On the other hand, genderwise trend analysis shows an increasing trend for male students while females are the opposite (Figure 2). Safe and healthy teaching-learning environments, better job opportunities, and societal encouragements are key factors to sustain and increase female enrollment in any university. 


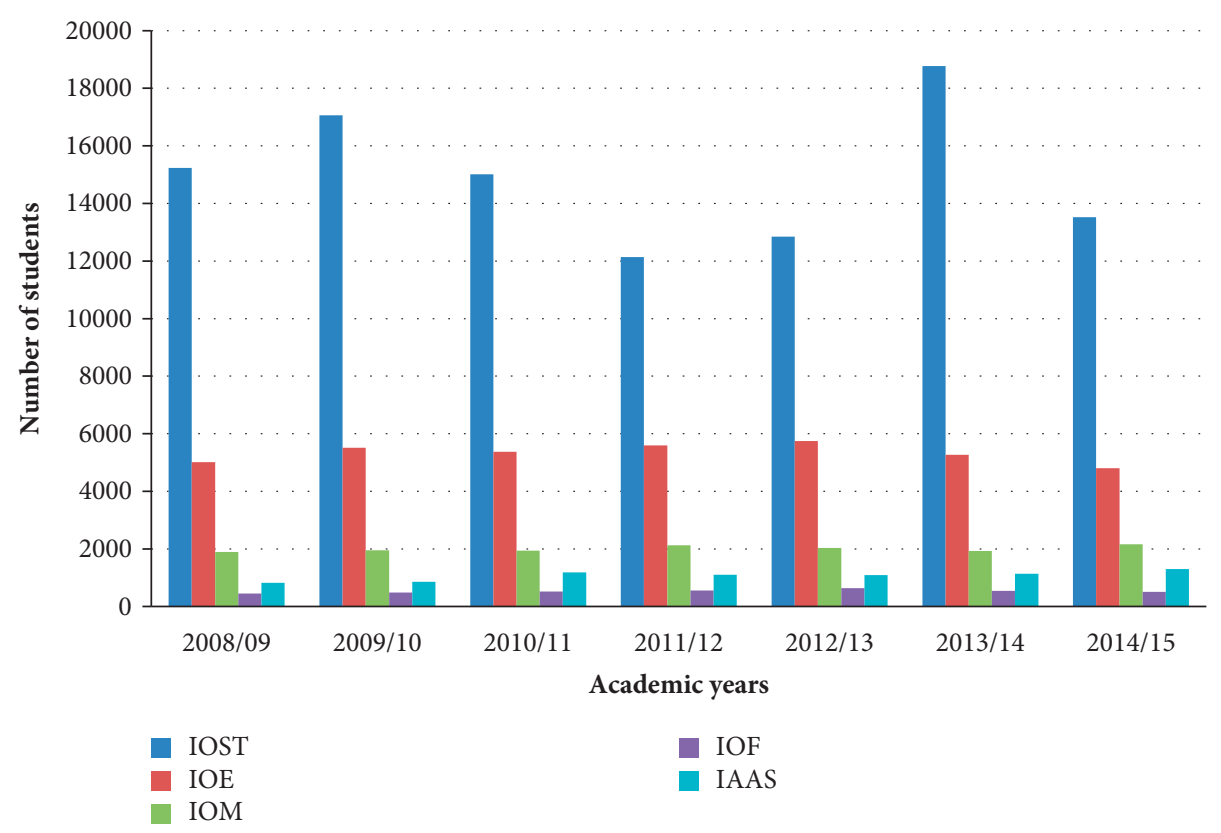

Figure 1: Enrollment trend at five institutes of TU.

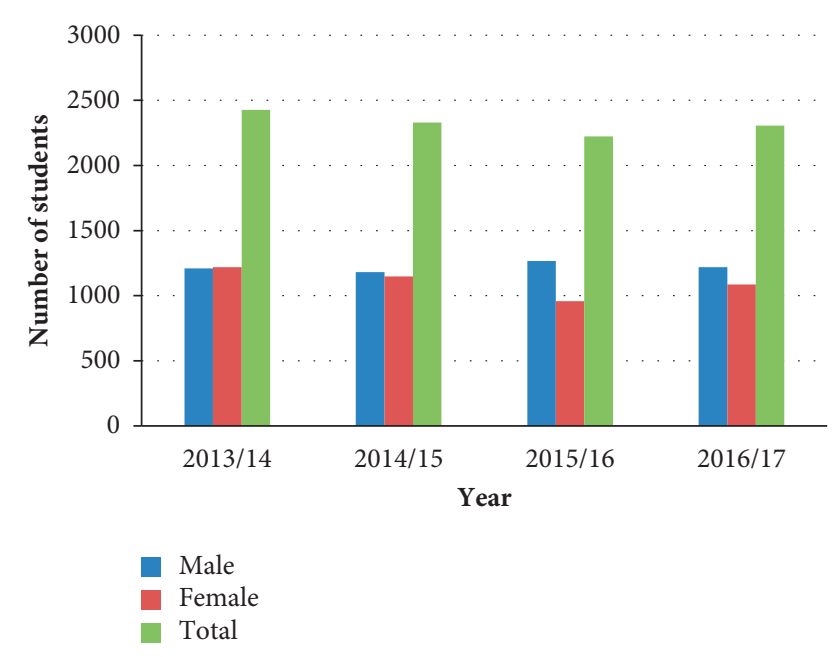

Figure 2: Enrollment trend of Kathmandu University in S\&T education.

Therefore, the university authority and government need to work together in facilitating the enrollment of female students. Providing scholarships to deserving female students and creating prospective jobs for female graduates are therefore of urgent importance in doing so.

\subsection{Key Bottlenecks}

3.2.1. Physical Infrastructure. Physical infrastructures are essential aspects of higher education. But, unfortunately, the development of infrastructure is not catching up as it should have been due to various reasons. Therefore, the study examined important areas of physical infrastructures, namely, classrooms, laboratories, and library which are key to sustaining S\&T education.
All the academic institutions (100\%) surveyed lacked a sufficient number of classrooms. Moreover, the existing classrooms were poorly maintained. Figure 3 shows the lighting conditions in the classrooms and laboratories of the surveyed institutions. The majority of the classrooms had poor lighting conditions (39.32\%) and inadequate lighting conditions (29.91\%). Only $6.84 \%$ and $19.66 \%$ of classrooms had very good and good lighting conditions, respectively. However, in $4.27 \%$ of the classrooms, there were no lighting facilities. The condition of the desk and bench was also not desirable. However, they were maintained, often covered with dust, litter, and so forth. All these need to be improved to attract more students towards S\&T education.

All the survey institutions (100\%) had separate laboratory facilities for different disciplines. However, the laboratories were having several problems within. Seating arrangements were not properly maintained and not adequate often. Adequate light is one of the prerequisites for a laboratory. However, the survey revealed that the lighting conditions were poor or inadequate in most laboratories. Significantly fewer numbers of laboratories had good and very good lighting conditions among the surveyed institutions.

However, the results showed no differences in the physical infrastructures among the academic institutions at the province level (Figure 4 ). Still, there are some differences as there were no lights in some classrooms in Province 1, Province 2, Province 3 (Bagmati Province), and Province 7 (Sudur Paschim Province). At the same time, the classrooms in Province 4 (Gandaki Province), Province 5, and Province 6 (Karnali Province) had higher proportions of classrooms with good and very good lighting conditions than Province 1, Province 2, Province 3, and Province 7. Unfortunately, classrooms at academic institutions from Province 7 had no very good lighting conditions at all. In all the classrooms of 


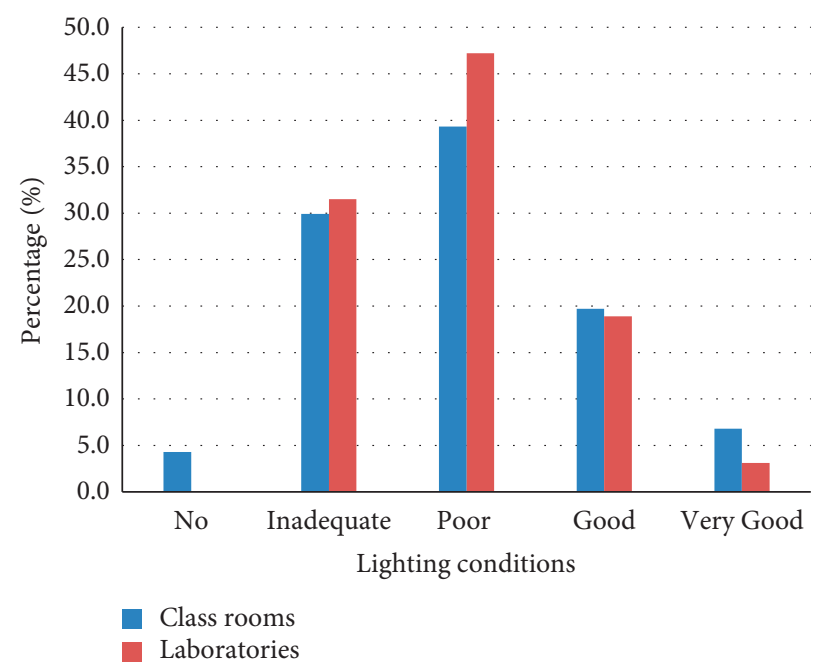

Figure 3: Status of lighting conditions in the classrooms and laboratories.

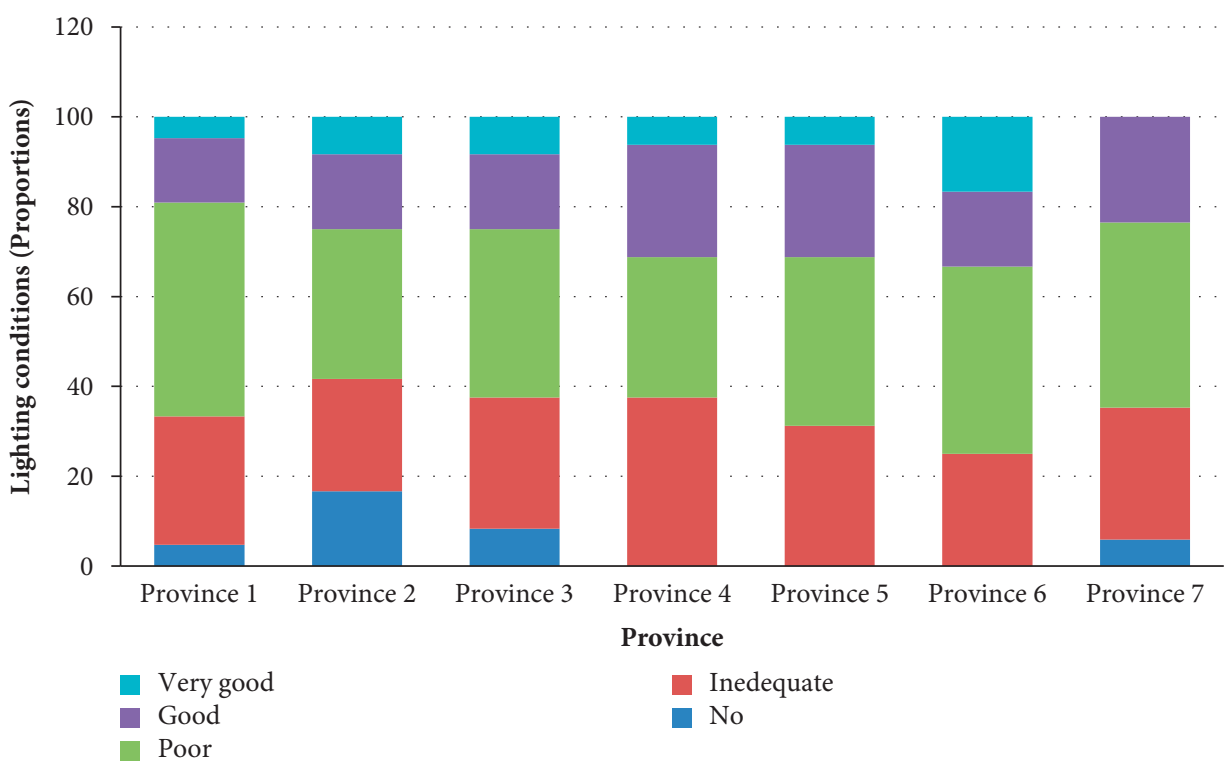

FIgURE 4: Provincewise lighting conditions in classrooms.

the sampled academic institutions, the desirable lighting conditions (good to very good) accounted for nearly $25 \%$. The remaining $75 \%$ of classrooms had undesirable (no to poor) lighting conditions.

The results showed that the proportion of laboratories with very good lighting conditions is very low. And the no single laboratory in Karnali Province and Sudur Paschim Province had very good lighting conditions (Figure 5). On the contrary, in all the provinces, the proportion of laboratories with poor lighting conditions was higher than other lighting conditions. Good to very good lighting conditions are desirable in laboratories. The proportions of the laboratories with these lighting conditions accounted for nearly $20 \%$ of the laboratories in the sampled academic institutions. The remaining $80 \%$ of laboratories had undesirable (no to poor) lighting conditions. Such issue has to be addressed as adequate/optimum lighting conditions are a prerequisite in the laboratories, which affect the health and safety of the students and instructors.

Figure 6 shows the provision of emergency exists and chemical storage facilities in the laboratories. Emergency exits were found only in seven laboratories, while there were no emergency exits in 127 laboratories. In the majority of the laboratories (51 out of 127 surveyed), there were no separate chemical storage facilities. Only 76 labs had separate chemical storage facilities. The use of personal protective equipment (PPE) was also not practiced in most laboratories except for gloves in few ones.

3.2.2. Human Resources. Adequate human resources were a critical problem in S\&T education. The survey revealed that, in all $100 \%$ of the institutions, there were shortages of human resources. The existing human resource is not 


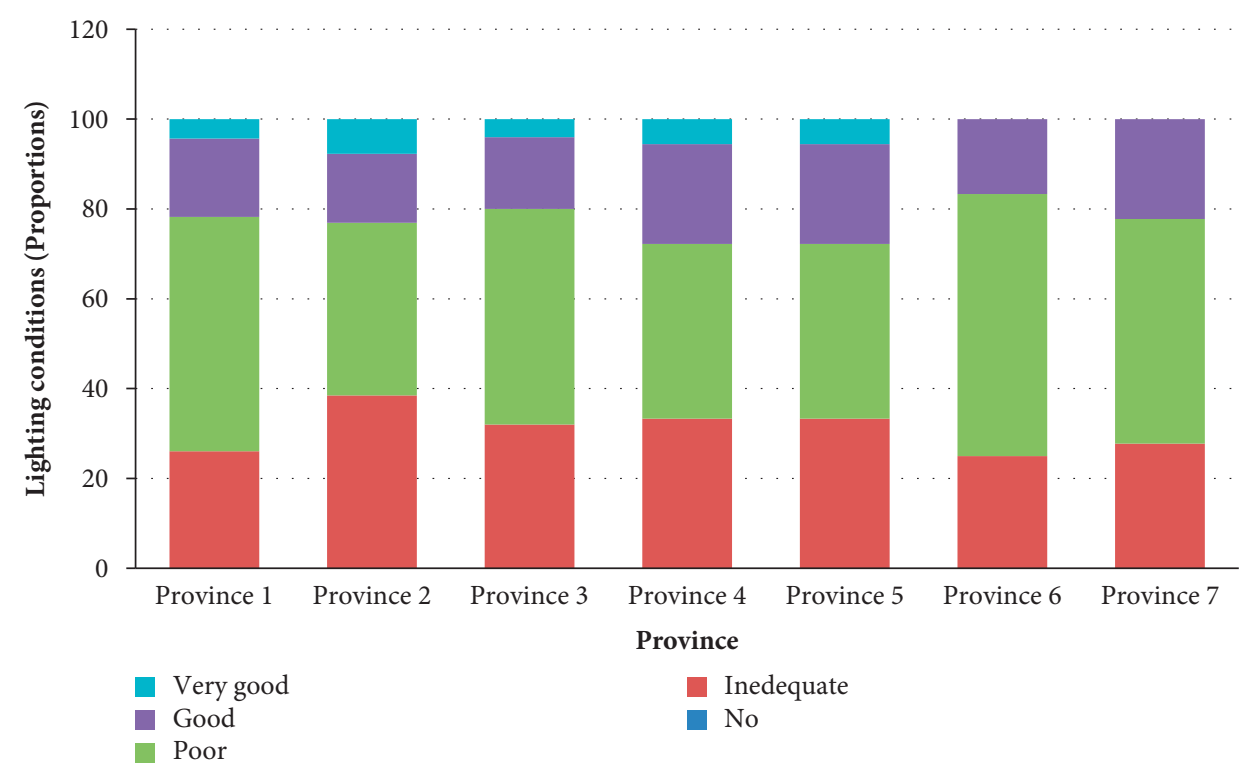

FIGURE 5: Provincewise lighting conditions in laboratories.

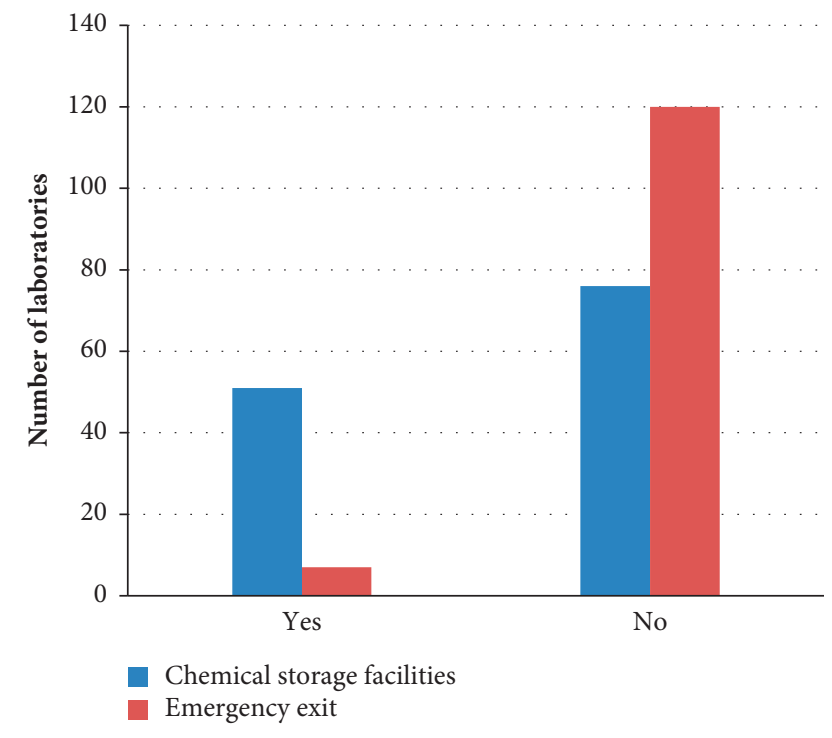

Figure 6: Provision of emergency exits and chemical storage facilities in laboratories.

appropriately trained with the latest development in S\&T education. Even, there are institutions where there was no permanent faculty at all. Consultation with the faculties revealed that $80.36 \%$ of faculties were not provided any training (Figure 7). Moreover, there was no provision of financial support to faculties for training and academic development in most academic institutions.

The creation of new knowledge through research is one of the key functions of universities. The research capacity of universities gives a good indication of the research capacity of countries. The practice of information technology in educational analysis helps to connect the individual to the world, but information technology (IT) is limited in surveyed academic institutions. To a large extent, faculties are not oriented

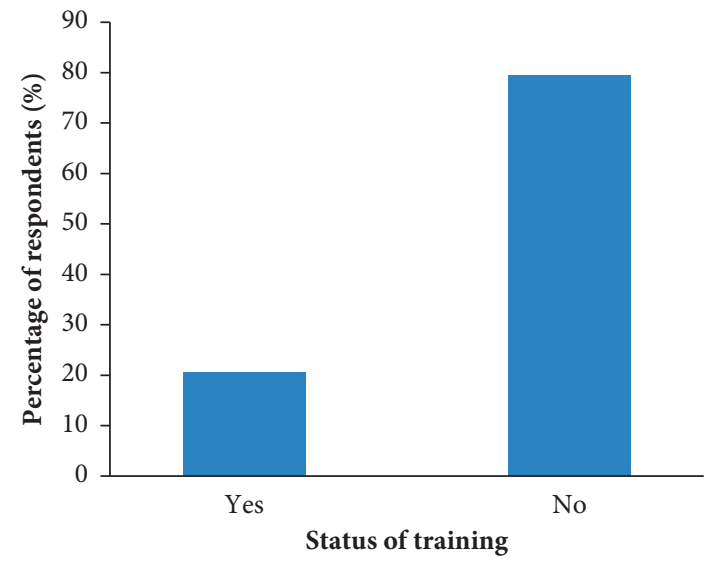

Figure 7: Status of training to faculties.

in IT in S\&T. The use of old software still exists, and there is a lack of new concepts. On the other hand, a bulk of research in any country takes place in universities and public research institutions, which receive substantial public funding, even in countries where big companies exist. However, in our case, the research environment needs significant development.

\subsubsection{Societal Perceptions of Science and Technology} Education. The survey revealed that the societal perception towards S\&T education is positive (76\%), showing a significant and exciting result (Figure 8). Despite decreasing trend in S\&T education, as shown earlier, society is still favorable towards it. So, if we consider improving several aspects to improve the situation, society is always there with positive attitudes for S\&T education. Consultation with the faculties, principals, and heads revealed that improvements were necessary for existing infrastructures, including classrooms, laboratories (including instruments/equipment), and libraries. 


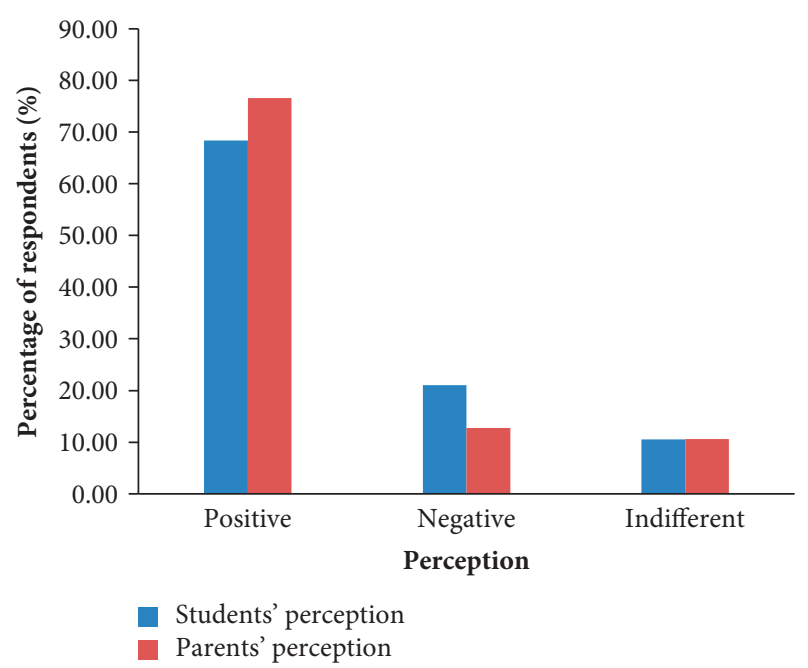

FIGURE 8: Societal perceptions towards S\&T education.

The survey team interacted with the students (from higher secondary schools, colleges, campuses, and universities) regarding their perceptions towards S\&T education in the country. The results showed that the students still bear positive perceptions towards S\&T education (68.42\%). However, the students would like to have better job opportunities in the country for the graduates of the S\&T education. Furthermore, the respondents opined that the science graduates need to do the additional degree on Bachelor of Education to qualify for teaching at schools (Teaching License). This has an additional burden to S\&T graduates and has to be restructured by incorporating an additional course on pedagogy/teaching in S\&T education as an elective course so that the prospective teachers would opt to take those subjects to qualify for the teaching profession.

\section{Discussion}

The major departure towards access to education, especially establishing higher education institutions offering science courses, was after opting for democracy during the fifties. Changes are continuing; however, the pace of changes towards access to higher education is relatively slow (about 15 percent only, almost less than half of the global average, and about 12 percent less than neighboring countries) [14]. Problems associated with access to higher education are multifaceted and interlinked due to the belief, and societal structure, especially preference towards enrolment in science and technology stream is very interesting from the recent past few decades [11]. The present study also found similar problems associated with higher education in Nepal.

The curriculum development has a minimal link with the skills and is not focused on the information and knowledge perspective. In each periodic plan, the policy, plans, and programs are drafted ritually. So, the human resources produced, although having academic credentials, generally lack skills and entrepreneurship. Over the past few years, many educated youths are moving abroad, searching for the labor market in unskilled or semiskill sectors only. Existing employment situation and economic growth patterns suggest that school and university curricula should enhance entrepreneurship skills to facilitate graduates from secondary schools to start small enterprises and engage in selfemployment $[12,15]$. Considering the present-day workingage population, involvement in the agriculture sector population seems to be declining from $64 \%$ to $32 \%$. In contrast, the service sector shows a shift from $21 \%$ to almost $43 \%$ by $2044 \mathrm{AD}$. Since the enrolment data on higher education at present is $80 \%$ in general stream compared to the $20 \%$ in science and technology stream, a reverse position of the same will make the above scenario possible, following the global trend of opting subjects like automation and artificial intelligence following fourth level industrial revolution trend [16].

The present study's finding at the enrolment trend of science and technology stream considering the largest university that accommodates students, Institute of Science and Technology and Institute of Engineering in Tribhuvan University, shows a decreasing trend from 2008 to 2015 whereas the Institute of Medicine (IOM), Institute of Forestry (IOF), and Institute of Agriculture and Animal Sciences (IAAS) show an increase, a reflection of the future trend. Since the nation has opted for a 70\% intake in Science and Technology and limiting general education to $30 \%$ to fulfill future human resources to address the development path, the enrolment scenario in S\&T institutes must be revisited. Improvement in the teaching-learning environments, creating better job opportunities for the graduates, and recognizing the importance of S\&T graduates in societal development are recommended as possible ways. The student enrollment number of Kathmandu University in S\&T programs between 2013/2014 and 2016/2017 also shows an overall decreasing trend. The male student intake outnumbers the female, not so encouraging social inclusion. Safe and healthy teaching-learning environments, better job opportunities, and societal encouragements are key to sustaining and increasing female enrollment in any university. Therefore, the university authority and government need to work together in facilitating the enrollment of female students. Policy incentives need to be considered from the government level.

Physical infrastructure is one of the key bottlenecks affecting Nepal's development in science and technology education. Physical infrastructure based upon the budget allocated from the national coffer hindered much. It was reflected in the conditions of classrooms, laboratories, libraries, lighting facilities, and others. Almost all surveyed institutions lacked sufficient classrooms, and those available classrooms were lacking regular maintenance too. Insufficient furniture in the classroom added with either absence or inadequate lighting facilities were shortcomings that may have affected S\&T education. Laboratories, a precondition for any S\&T learning, were present in the surveyed institutions; however, inadequate facilities contributed to the limitation of the understanding properly. A scenario explained in the result section above showing almost $80 \%$ of the institutions with poor to inadequate lighting conditions in the laboratories impact the learning of S\&T education. A 
few institutions in Provinces 1, 2, 3, and 7 were observed, even providing no light in the laboratories.

Proper storage, emergency, and personal protective equipment (PPE), a normal standard maintained globally in academic institutions, were not found in most institutes. Although about a half of the surveyed institutions were having a facility of separate storage facilities, emergency exits were not found in most of them. Only gloves are maintained as PPEs, and these are the observed bottlenecks in expanding access to S\&T education in the country.

Quality infrastructures, including well-equipped laboratories and resourceful libraries, are prerequisites for S\&T education. Empirical evidence is suggesting a direct relationship between infrastructure and education performance. Better infrastructure quality and other educational facilities impart positive effects on learning among students [17]. It is a fact that having schools in good conditions is decisive for students to achieve the expected academic results [7, 18-21]. There can be no doubt that considerable effort should be put into scientific and technical education, and such education cannot flourish without some university-based research effort $[1,14]$.

Regarding human resources, secondary information collected from official government sources, verified with the field data collected, tallies properly with the study carried out by the Government of Nepal [16]. There is no balance between the teachers' demand and supply side from secondary to university level, which is somewhat skewed. Even in the subjects having adequacy, most of them lack proper training in skills and information technology. The existing education system is teacher-centric, lacking contemporary transformation to the young minds. On the other hand, a bulk of research in any country takes place in universities and public research institutions, which receive substantial public funding, even in countries where big companies exist. However, in the case of Nepal, the research is still not the priority of national policy, and the research environment needs substantial development.

School, family, and cultural factors play a significant role in students' choices to study STEM at University [22]. In the present study findings, eligibility criteria in the science stream were related to the higher grades at school/higher secondary levels, not with the understanding and delivery competency of the particular students. It is generally perceived in Nepal that STEM education is for children from wealthy and upper-class families. Such perception also affects access to STEM education in Nepal, mainly from poor and lower-class families. Subject choice is often related to career choice and research trends to follow a psychological or a sociological approach [23]. Research with a sociological focus typically considers structural factors. Available opportunities (beyond merely the subjects available) play an important role in developing occupational and educational aspirations [24].

Several factors influence female participation in S\&T education. In Nigeria, for example, home, education institution, and society are important factors influencing female participation in S\&T education [25]. The role of scholarships and financial aids is also significant in college choice, subject choice, progression, and timely graduation [26-28]. Therefore, access to scholarships and financial resources is key to increasing and retaining female students in Nepalese colleges and universities. On the other hand, the relationship between the general public's understanding of science and the attitude towards public funding of scientific research is equally important for the sustainability of education support [29]. There is a strong and continuing general belief in the value of scientific research for economic prosperity and the quality of life [30]. Strong interest in and knowledge about science in society is associated with more favorable attitudes towards science. This positive attitude, in turn, affects support for public funding of science [31].

\section{Conclusions}

The fundamental bottleneck in expanding access to Science and Technology (S\&T) education in Nepal is the policy ambiguity. The stable government came after almost half a century history of the country with a slogan of "prosperous and developed Nepal"; however, the direction was not defined. The education policy document mentioned $70 \%$ of human resources would be in the Science and Technology sector and $30 \%$ in general education. Assessment of $\mathrm{Hu}-$ man Resource Projection for the coming 25 years till 2044 AD. had a vivid picture of the need for Science and Technology human resources. However, institutional mapping, related resources required are in the process of study. The share of Gross Domestic Product and National Budget allocated in the education sector is relatively low. A significant chunk of that goes to the salary part. Higher education and especially S\&T education is still not a higher priority. Students' enrollment in S\&T education at the university level in Nepal is decreasing, as shown by the present study. Physical infrastructure, namely, classrooms, laboratories, and libraries, has been identified as other bottlenecks in expanding the S\&T education along with capable and trained teaching faculty. This needs to be looked at seriously to improve S\&T education as many campuses/colleges depend upon part-timers to run the S\&T education programs. Better coordination among faculties, staff, management, and other stakeholders would benefit all those involved in S\&T education. Similarly, the societal impression on opting for S\&T linked with economic and social hierarchy needs to change.

\section{Data Availability}

In this research, two types of data are used: (a) the field data collected by the researchers and (b) the secondary data published by governmental and nongovernmental organizations. Most of the data used to support the findings of this study are included within the article. The processed field data used to support the findings of this study are available from the corresponding author upon request. The secondary data used to support the findings of this study are available from the corresponding author /organization upon request. 


\section{Disclosure}

The funder had no role in the design of the study; the collection, analyses, or interpretation of data; the writing of the manuscript; or the decision to publish the results.

\section{Conflicts of Interest}

The authors declare no conflicts of interest.

\section{Acknowledgments}

The authors would like to thank Dr. Dipak Khadka and Dr. Hridaya Ratna Bajracharya for their valuable suggestions and inputs during the research. Thanks are also due to $\mathrm{Mr}$. Roshan Poudel, Ms. Sijal Pokhrel, Mr. Krishnahari Acharya, and Mr. Raju Thapa for their help during the field survey. This research was funded by the University Grants Commission (UGC), Nepal (Grant no. SR-73/74-Edu-02), and the APC was funded partially by the grant.

\section{References}

[1] J. R. Gass, "Science and science education in developing countries," International Review of Education, vol. 10, no. 1, pp. 77-84, 1964.

[2] D. G. Chisman, "Science education and national development," Science Education, vol. 68, no. 5, pp. 563-569, 1984.

[3] Organization for Economic Development and Corporation, Tertiary Education for the Knowledge Society, OECD Thematic Review of Tertiary Education, Organization for Economic Development and Corporation, Paris, France, 2008.

[4] The World Bank, Constructing Knowledge Societies: New Challenges of Tertiary Education, The World Bank, Washington, DC, USA, 2002.

[5] P. Pillay, Higher Education and Economic Development: Literature Review, Centre for Higher Education Transformation (CHET), Cape Town, South Africa, 2011.

[6] J. Khan, "The role of research and development in economic growth: a review," Journal of Economics Bibliography, vol. 2, no. 3, pp. 128-133, 2015.

[7] G. Tassey, "The functions of technology infrastructure in a competitive economy," Research Policy, vol. 20, no. 4, pp. 345-361, 1991.

[8] UNESCO, Global Observatory of Science, Technology and Innovation Policy Instruments (GO-SPIN), UNESCO, Paris, France, 2020.

[9] MOEST, National Science, Technology and Innovation Policy, 2019, Kathmandu: Government of Nepal, Ministry of Education, Science and Technology, Kathmandu, Nepal, 2019.

[10] B. Pangeni, "Tribhuvan Vishwavidyalaya Ko Itihas (BS 2016 to 2039)", Volume, Vol. 1, Tribhuvan University, Kathmandu, Nepal, 2019.

[11] R. M. Singh and D. R. Bhuju, "Development of science and technology in Nepal," Science Technology \& Society, vol. 6, no. 1, pp. 159-178, 2001.

[12] Asian Development Bank, Private Higher Education Across Asia: Expanding Access, Searching for Quality, Asian Development Bank, Manila, Philippines, 2012.
[13] Central Bureau of Statistics, Nepal Living Standards Survey 2010/11, Vol. 1, Central Bureau of Statistics, Kathmandu, Nepal, 2011.

[14] R. D. Joshi, Higher Education in Nepal: Supporting Aspirations for Prosperity, Education for Community, Kathmandu, Nepal, 2018.

[15] HLNEC/GoN, High Level National Education Commission Report, Ministry of Education, Science and Technology, Government of Nepal, Kathmandu, Nepal, 2018.

[16] MoEST/GoN, Assessment of Human Resource Status and Projection for Prosperous and Developed Nepal (2019-2044 A.D.), MoEST/GoN, Kathmandu, Nepal, 2019.

[17] E. A. Hanushek, "Interpreting recent research on schooling in developing countries," The World Bank Research Observer, vol. 10, no. 2, pp. 227-246, 1995.

[18] J. Buckley, M. Schneider, and Y. Shang, "Fix it and they might stay: school facility quality and teacher retention in Washington, D.C," Teachers College Record, vol. 107, no. 5, pp. 1107-1123, 2005.

[19] V. Durán-Narucki, "School building condition, school attendance, and academic achievement in New York city public schools: a mediation model," Journal of Environmental Psychology, vol. 28, no. 3, pp. 278-286, 2008.

[20] L. O. Picus, S. F. Marion, N. Calvo, and W. J. Glenn, "Understanding the relationship between student achievement and the quality of educational facilities: evidence from wyoming," Peabody Journal of Education, vol. 80, no. 3, pp. 71-95, 2005.

[21] K. Tanner, "Effects of school design on student outcomes," Journal of Educational Administration, vol. 47, no. 3, pp. 376-394, 2009.

[22] B. C. Panther, J. Moose, and C. Bottrell, "Factors affecting student motivation for STEM study," in Proceedings of the Australian Conference on Science And Mathematics Education, Canberra, Australia, 2015.

[23] G. V. D. Vyver, D. Crabb, and M. S. Lane, "Factors influencing the decision to choose information technology preparatory studies in secondary schools: an exploratory study in regional/ rural Australia," Issues in Informing Science and Information Technology, vol. 1, pp. 729-739, 2004.

[24] A. Furlong and F. Cartmel, "Aspirations and opportunity structures: 13-year-olds in areas with restricted opportunities," British Journal of Guidance and Counselling, vol. 23, no. 3, pp. 361-375, 1995.

[25] C. N. Maryann and C. A. Patience, "Investigating factors influencing girl's participation in science and technology education in Nigeria," IOSR Journal of Research \& Method in Education, vol. 7, no. 3, pp. 50-54, 2017.

[26] N. M. Ganem and M. Manasse, "The relationships between scholarships and student success: an art and design case study," Educational Research International, vol. 2011, Article ID 743120, 8 pages, 2011.

[27] L. D. Singell, "Come and stay a while: does financial aid effect retention conditioned on enrollment at a large public university?" Economics of Education Review, vol. 23, no. 5, pp. 459-471, 2004.

[28] R. Chen and S. L. DesJardins, "Exploring the effects of financial aid on the gap in student dropout risks by income level," Research in Higher Education, vol. 49, no. 1, pp. 1-18, 2008.

[29] A. Muñoz, C. Moreno, and J. L. Luján, "Who is willing to pay for science? on the relationship between public perception of science and the attitude to public funding of science," Public Understanding of Science, vol. 21, no. 2, pp. 242-253, 2010. 
[30] J. D. Miller, "Public understanding of, and attitudes toward, scientific research: what we know and what we need to know," Public Understanding of Science, vol. 13, no. 3, pp. 273-294, 2004.

[31] L. Guenther and P. Weingart, "A unique fingerprint? factors influencing attitudes towards science and technology in south Africa," South African Journal of Science, vol. 112, no. 7-8, pp. 1-4, 2016. 